\title{
Biochemical Correlations in Peritoneal Sepsis in Children
}

\author{
CRISTINA SERBAN ${ }^{1,2}$, DOREL FIRESCU ${ }^{1,2}$, LAURA REBEGEA ${ }^{3,4 *}$, CORINA PALIVAN MANOLE ${ }^{4}$, DRAGOS VOICU \\ ${ }^{1}$ Sf. Ap. Andrei Emergency Clinical Hospital, Surgery Clinic II, 177 Brailei Str., 800578,Galati, Romania \\ 2Dunarea de J os University of Galati, Faculty of Medicine and Pharmacy, Surgical Clinical Department, 47 Domneasca Str., 800008, \\ Galati, Romania \\ ${ }^{3}$ Sf. Ap. Andrei Emergency Clinical Hospital, Department of Radiotherapy, 177 Brailei Str., 800578, Galati, Romania \\ ${ }^{4}$ Dunarea de J os University of Galati, Faculty of Medicine and Pharmacy, Medical Clinical Department, 47 Domneasca Str., 800008, \\ Galati, Romania \\ The biochemical analysis in acute peritonitis follows the assessment of the objective severity degree sustained \\ by endotoxicosis, homeostasis disorders and acid-base balance. We had monitored the biochemical \\ peculiarities and correlations in acute peritonitis in children during a retrospective study statistically analyzed \\ on a group of 127 patients in the period 2009-2014. The obtained results were consistent with the form and \\ late phase of peritonitis.
}

Keywords: peritonitis, biochemistry, alterations

Despite the scientific progress in the last decades, the degree of systemic endothelial damage in acute peritonitis in children remains a topical issue in scientific research due to the complications they cause, with a frequency ranging from $10 \%$ to $35.5 \%$ [1 - 3].

According to literature data, it is known that an extracellular dehydration characterized by osmotic pressure depletion occurs in most patients with purulent peritonitis, in the conditions of negligible deviation of electrolytes as compared to the normal limits [4-6]. But in the case of severe peritonitis [13], the osmotic pressure increases (intracellular dehydration), which does not depend on electrolyte disturbances, but is conditioned by the formation of biologically active substances, which determines the degree of intoxication $[4,5]$.

The academic studies are poor in results on the particularities of the biochemical examination and on the assessment of the severity degree of acute peritonitis in children, which justifies the actuality of this study.

\section{Experimental part}

Material and method

We performed a retrospective study on a number of 127 patients admitted and treated in the Pediatric Clinic Section of Sf. Ioan Emergency Clinical Hospital for Children, Galati and in Surgery Clinic II of Sf. Ap. Andrei Emergency Clinical Hospital, Galati, during 2009-2014.

The inclusion criteria were age between 0 months and 18 years old and the presence of signs of peritonitis and endotoxicosis.

The statistical analysis was carried out with the XLSTAT 2017, program using descriptive analytical methods, univarious and multivarious statistical analytical methods: average / median, standard deviation, box-plot diagrams, media comparison tests, Student, ANOVA, Pearson correlation coefficient, main component analysis (correlation circle and biplot diagrams).

The degree of statistical significance has been set according to the values of the parameter $p$ :

$-p<0.05$, the difference between the two averages is significant;

$-p<0.01$, the difference between the two averages is highly significant;

$-p<0.001$, the difference between the two averages is very highly significant; $-p>0.05$, the difference between the two averages is insignificant;

Table 1

ANALYZED STATISTICAL PARAMETERS

\begin{tabular}{|l|c|}
\hline \multicolumn{1}{|c|}{ Analyzed parameter } & Number of patients (\%) \\
Median age (years old) (interval) & $13(0.01-18)$ \\
Age groups (years old) & $23(18.11)$ \\
$0-6$ & $37(29.13)$ \\
$7-12$ & $67(52.76)$ \\
$13-18$ & $74(58.26)$ \\
Sex & $53(41.73)$ \\
Male & $41(32.28)$ \\
Female & $86(67.72)$ \\
Origin environment & $56(44.09)$ \\
Urban & $12(9.45)$ \\
Rural & $6(4.72)$ \\
Peritonitis etiology & $53(41.73)$ \\
- acute appendicitis & \\
- diverticulitis $\quad$ invagination & \\
\hline
\end{tabular}

\section{Results and discussions}

The incidence of cases according to the age group revealed the frequency of the interval 13-18 years old in $52.76 \%$ cases, corresponding to the period of maximal development of the lymphatic system and to the prevalence of appendicular etiology of peritonitis. The greatest difference between the average and the median was observed at the age parameter, which varied within wide limits: the average age $=11.658$ years old and the median $=13$ years old.

The male sex was affected in $58.25 \%$ cases, as compared to the female sex, which was affected in $41.73 \%$ cases out of the analyzed cases.

In the 127 cases of peritonitis in children, a significantly higher incidence had been observed in the rural patients, $67.72 \%$, as compared to ones from the urban environment, $32.28 \%$, which can be explained by the poor quality of healthcare in the territory and by the delay in diagnosis, their coming to the hospital being already late, in the complication stage.

The appendicular peritonitis had prevailed in $44.09 \%$ cases, where the following were considered as contributing factors: late addressability, diagnostic errors 


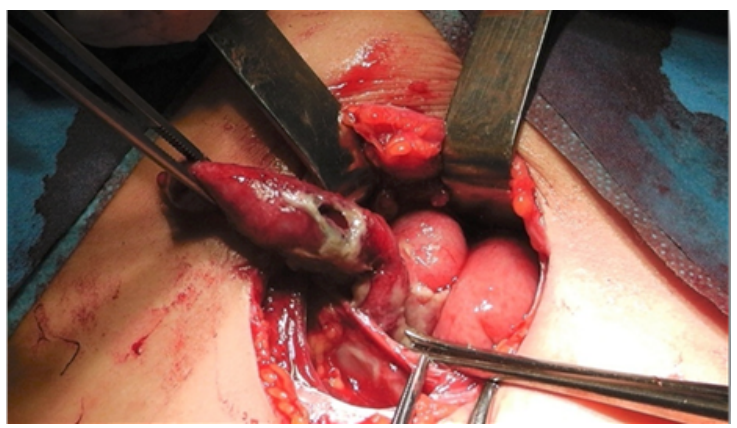

Fig. 1. Perforated gangrenous appendicitis with localized peritonitis, intra-surgical aspect Pediatric Surgery Department, Sf.Ioan Children's Hospital

due to the atypical manifestations of the acute appendicitis and the low age of children.

The time interval between symptomatology's onset and admission to hospital was the most frequent for $24-48 \mathrm{~h}$ in $40.16 \%$ cases, followed by those for $48-72$ hin $25.2 \%$ cases and those for over $72 \mathrm{~h}$ in $22.05 \%$ cases.

Table 2

THE RESULTS OF LABORATORY EXPLORATIONS

\begin{tabular}{|l|c|}
\hline $\begin{array}{l}\text { Hematological/biochemical } \\
\text { constants }\end{array}$ & Values \\
\hline Hb values at admission & $11.9(8.2-15.8)$ \\
into hospital (g/d) & $11.99( \pm 1.54)$ \\
Median, (interval, min- & \\
max) & \\
Average ( $\pm \mathrm{DS})$ & \\
& \\
Ht values at admission into & $33.7(22.5-46.3)$ \\
hospital $(\%)$ & $33.83( \pm 4.18)$ \\
Median, (interval, min- & \\
max) & \\
Average ( $\pm \mathrm{DS})$ & \\
Electrolyte values & $23(18.11)$ \\
Low & $104(81.89)$ \\
Normal values & \\
& \\
Alkaline reserve & $23(18.11)$ \\
Low & $104(81.89)$ \\
\hline Normal values & \\
\hline
\end{tabular}

The hydro-electrolyte imbalances induced in the set-up and evolution of peritonitis were monitored through electrolyte values and alkaline reserve. Changes were noted in $18.11 \%$ of cases, present particularly in the case of severe neglected peritonitis.
Negative correlations between onset - admission to hospital and $\mathrm{Hb}$, Ht and electrolyte values were identified, in the sense that, with the increase of the time interval between the onset of the symptoms and the time of admission to hospital, the values of the above mentioned hematological constants showed lower values.

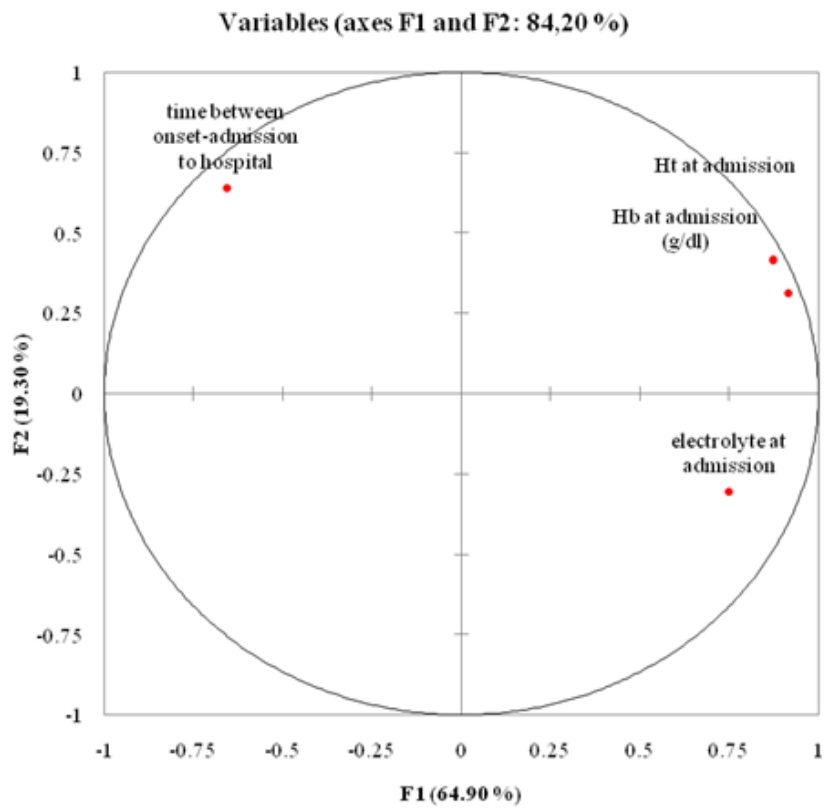

Fig. 2. The circle of correlations on the time between onset and admission to hospital with: $\mathrm{Hb}, \mathrm{Ht}$, electrolyte at admission

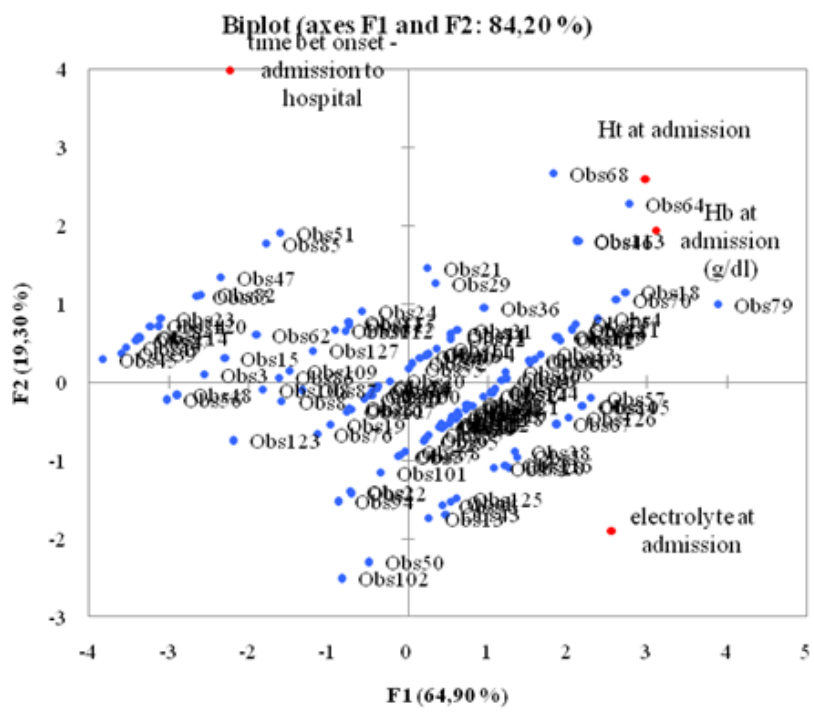

Fig. 3. Biplot chart for the time between onset and admission to hospital and admission with: $\mathrm{Hb}, \mathrm{Ht}$, electrolyte at admission

Table 3

CORRELATION MATRIX BETWEEN ONSET - ADMISSION TO HOSPITAL WITH: Hb AT ADMISSION TO HOSPITAL, Ht AT ADMISSION TO HOSPITAL, LOW ELECTROLYTE

\begin{tabular}{|l|c|c|c|c|}
\hline \multicolumn{1}{|c|}{ Correlation matrix. Pearson Coefficients } \\
\hline \multicolumn{1}{|c|}{ Variables } & $\begin{array}{c}\text { Time between } \\
\text { onset - } \\
\text { admission to } \\
\text { hospital }\end{array}$ & $\begin{array}{c}\text { Hb at admission to } \\
\text { hospital (g/dl) }\end{array}$ & $\begin{array}{c}\text { Ht at admission } \\
\text { to hospital }\end{array}$ & $\begin{array}{c}\text { Electrolyte at } \\
\text { admission to } \\
\text { hospital }\end{array}$ \\
\hline $\begin{array}{l}\text { Time between onset - } \\
\text { admission to hospital }\end{array}$ & $\mathbf{l}$ & -0.432 & -0.359 & -0.455 \\
\hline $\begin{array}{l}\text { Hb at admission to hospital } \\
\text { (g/dl) }\end{array}$ & -0.432 & $\mathbf{l}$ & 0.886 & 0.537 \\
\hline Ht at admission to hospital & -0.359 & 0.886 & $\mathbf{1}$ & \\
\hline $\begin{array}{l}\text { Electrolyte at admission to } \\
\text { hospital }\end{array}$ & -0.455 & 0.537 & 0.463 & \\
\hline
\end{tabular}


Table 4

CORRELATION MATRIX BETWEEN THE OCCLUSIVE STAGE AND Hb, Ht, ELECTROLYTE VALUES

\begin{tabular}{|c|c|c|c|c|c|}
\hline Variables & $\begin{array}{l}\text { Occlusive stage of } \\
\text { peritonitis }\end{array}$ & $\begin{array}{l}\mathrm{Hb} \text { at admission } \\
\text { to hospital (g/dl) }\end{array}$ & $\begin{array}{l}\text { Ht at admission } \\
\text { to hospital }\end{array}$ & $\begin{array}{l}\text { Electrolyte values at } \\
\text { admission to hospital }\end{array}$ & $\begin{array}{l}\text { Age } \\
\text { (years } \\
\text { old) }\end{array}$ \\
\hline $\begin{array}{l}\text { Occlusive stage of } \\
\text { peritonitis }\end{array}$ & $1^{--}$ & $-0,416$ & $-0,340$ & $-0,500$ & $0,014^{-}$ \\
\hline $\begin{array}{l}\mathrm{Hb} \text { at admission to } \\
\text { hospital (g/dl) }\end{array}$ & $-0,416$ & 1 & 0,886 & 0,537 & $0,434^{-}$ \\
\hline $\begin{array}{l}\mathrm{Ht} \text { at admission to } \\
\text { hospital }\end{array}$ & $-0,340$ & $0,886^{-}$ & 1 & $0,463^{-}$ & $0,467^{-}$ \\
\hline $\begin{array}{l}\text { Electrolyte values at } \\
\text { admission to hospital }\end{array}$ & $-0,500$ & $0,537^{-}$ & 0,463 & 1 & 0,128 \\
\hline $\begin{array}{c}\text { Age } \\
\text { (years old) }\end{array}$ & 0,014 & $0,434^{-}$ & 0,467 & 0,128 & $\mathrm{I}^{-}$ \\
\hline
\end{tabular}

The occlusive stage of peritonitis had correlated negatively and strongly with $\mathrm{Hb}$ and, respectively, with electrolyte values at admission, $\mathrm{CP}=-0.416$ respectively, $\mathrm{CP}=0.5$. A negative but weak correlation occurred between occlusive status and $\mathrm{Ht}$ values at admission, CP $=-0.340$. The patients with occlusive peritonitis presented lower $\mathrm{Hb}$, Ht and electrolyte values at admission to hospital.

Also, strong and positive correlations were recorded between $\mathrm{Hb}$ values and $\mathrm{Ht}$ values $(\mathrm{CP}=0.886)$ and electrolyte values at admission to hospital $(C P=0.537)$. Variables (axes F1 and F2: 78,48\%)

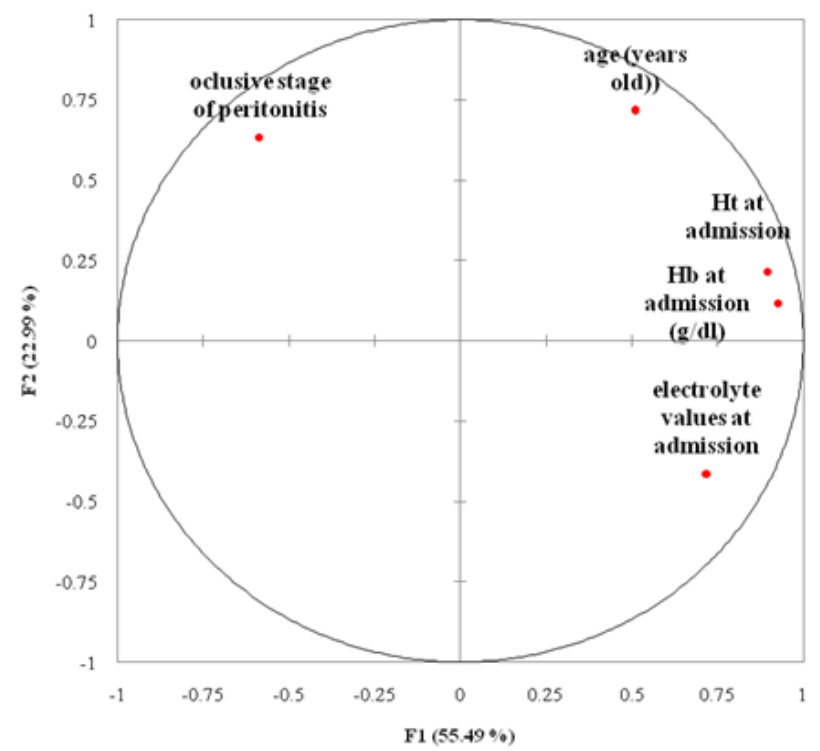

Fig. 4. Circle of correlations between the occlusive stage and $\mathrm{Hb}$, $\mathrm{Ht}$, electrolyte values

The data from the literature suggest that acid-base balance plays a decisive role in the regulation of hydrosaline metabolism through mutual interaction [7, 8]. Acidic products constantly penetrate the body as a result of cellular anaerobic metabolism. In the case of hepato-renal damage, these products cannot be metabolized. Under the conditions of acute peritonitis, intensification of metabolism occurs with increasing the energy use. The low energy input and the increased excretion of metabolites, electrolytes and water, lead to the depletion of carbohydrate reserves and the use of lipid and protein reserves as an energy substrate. As a result of the breakdown of these substances, lactic products, acids ketone compounds, oxybutyric acid, lactic acid, pyruvic acid are formed, which further aggravates acidosis. In addition, oligoanuria, the decrease of the circulating blood volume, alkaline loss simultaneously with vomiting, diarrheal stools, lead to tissue hypoxia, lactic acid accumulation and other acidic compounds [9-11].

Dyspnea occurs in children with peritonitis, which in connection with algic syndrome and the limitation of diaphragm movements, a rapid pulmonary decompensation for eliminating these products occurs, and simultaneously with the diminishing of the renal flow, the renal excretion decreases and subcompensated metabolic acidosis passes into the decompensated phase $[12,14]$.

\section{Conclusions}

Concepts on the diagnosis of acute peritonitis are based on clinical signs, supplemented with laboratory and imaging data.

Depending on the acute peritonitis form and phase and the correlation with the biochemical data, it is possible to adopt an appropriate therapeutic attitude, differentiated by the endotoxicosis severity degree.

\section{References}

1.ABRAHAM M.K. et al. A simple and safe technique for pneumatic reduction of intussusception. In: Asian J Surg, 2006, vol. 29, p. 170177.

2.AGARWAL H.S. et al. Hemorrhagic stress ulceration in a case of appendicitis. In: J Pediatr Surg, 2006, vol. 41, nr. 8, p. 1483-1485.

3.ALLEN L., The peritoneal stomata / Anat. Rec., 1936 / 67-89

4.J AMIESON D.H., CHAIT P.G., FILLER R. Interventional drainage of appendiceal abscesses in children. In: AJR Am J Roentgenol, 1997, vol. 169, p. 1619-1622.

5.LO A.Y., BEATON H.L. Selective management of colonoscopic perforations. In: J Am Coll Surg, 1994, vol. 179, p. 333-337.

6.MAXWELL R.A. etal. Secondary abdominal compartment syndrome: in underappreciated manifestation of serve hemorrhagic shock. In: J Trauma, 1999, vol. 47, p. 995-999

7.KATZ S. Liver bacterial clearance following hepatic artery ligation and portacaval shunt. In: J Surg Res, 1991, vol. 51, p. 267-270.

8.ST. PETER S.D. et al. Initial laparoscopic appendectomy versus initial nonoperative management and interval appendectomy for perforated appendicitis with abscess: a prospective, randomized trial. In: J Pediatr Surg, 2010, vol. 45, p. 236-240.

9.EIJKE J.C. et al. Outcomes of children with abdominal compartment syndrome. In: Acta Clin Belg Suppl, 2007, vol. 1, p. 141-148.

10.GAGNER M. et al. Early experience with laparoscopic approach for adrenalectomy. In: Surgery (St. Louis), 1993, vol. 114, p. 1120-1125.

11.SCHLINKERT R.T., RASMUSSEN T.E. Laparoscopic repair of colonoscopic perforations of the colon. In: J Laparoendosc Surg, 1994, vol. 4, p. 51-54.

12.FORGUESD. et al. Post-appendectomy intra-abdominal abscessescan they successfully be managed with the sole use of antibiotic therapy? In: Eur J Pediatr Surg, 2007, vol. 17, p. 104-109

13.FIRESCU, D., SERBAN, C., NECHITA, A., DUMITRU, M., REBEGEA, $L$., Age influence in the prognosis of bacterial secondary peritonitis, Rev. Chim. (Bucharest), 68, no.5, 2018, p. 1023-1027

14.KODIKARA H. et al. Ten-year review of intussusception at Starship Hospital: 1998-2007. In: N Z Med J, 2010, vol. 15, nr. 123, p. 32-40.

Manuscript received: 7.01 .2019 